\title{
Adolescent sex and 'defilement' in Malawi law and society
}

\author{
Godfrey D Kangaude*
}

LLD Candidate, Department of Private Law, University of Pretoria, South Africa

\section{Summary}

During colonisation Malawi received a Western penal code, which included the 'defilement' provision, restricting males from sexually accessing girls below a specified age. Countries that maintain colonial age of consent provisions, including Malawi, have uncritically assumed that these laws serve the purpose of protecting girls and children from harm. This article examines the fundamental assumptions underlying the development of sections 138 and $160 B$ of the Malawian Penal Code, and their historical and sociocultural origins. The article submits that these provisions serve the interests of adults and not those of children. They are inherently heterosexist, promote gender-stereotypical meanings of sexuality and potentially stigmatise the normative development of sexuality in children. Sections 138 and $160 B$ need to be reviewed and aligned with Malawi's commitments to promote gender equality and sexual health and the rights of children.

Key words: childhood sexuality; child rights; Gender Equality Act, age of consent, Malawi Penal Code manuscript respectively. 


\section{Introduction}

On 1 April 1930, Malawi enacted its current Penal Code $^{1}$ which was based on the Colonial Office model code drafted by Albert Ehrhardt, which he based on the Nigerian Code of 1916, itself based on the Queensland Code of $1899 .^{2}$ Section 138 of the Penal Code (section 138), the 'defilement provision', restricts boys and men from sexually accessing girls below a specified age. The defilement provision is part of what broadly are referred to as 'age of consent' ${ }^{3}$ provisions or laws. Section 138 regulates the age of consent to sexual intercourse. Originally, the age of consent was 13 years, but in 2000 the Malawi Law Commission recommended that it be raised to 16 years. ${ }^{4}$ In 2010, parliament passed a Bill to implement the recommendations of the Malawi Law Commission. ${ }^{5}$ The suggested amendments to the Penal Code were enacted and entered into force in 2011. Section $160 \mathrm{~B}$ of the Penal Code (section 160B), which criminalises sexual activity with a child below 16 years of age, was at this time introduced. From the perspective of World Vision, a view probably representative of most stakeholders in Malawi, the intention behind the amendments was to enhance the protection of the girl child from sexual abuse. ${ }^{6}$ The aim of this article is to explore the rationale and assumptions behind the development of sections 138 and 160B in view of Malawi's commitment to promote gender equality and the sexual health and rights of children.

Sections 138 and 160B must be understood in their historical, sociocultural and political contexts, beginning with their colonial origins, and including the legal developments that have since taken place. Most significantly, in 1994 Malawi adopted a democratic Constitution which includes a Bill of Rights. 7 Section 23 of the Constitution of Malawi (Constitution) recognises the rights of children. Another significant event was the enactment and entry into force of the Gender Equality Act in $2013 .^{8}$ This Act aims at addressing gender inequality between men and women. It also recognises the

1 Ch 7:01 Laws of Malawi, Penal Code 1930.

2 HF Morris 'A history of the adoption of codes of criminal law and procedure in British colonial Africa, 1876-1935' (1974) 18 Journal of African Law 1822.

$3 \mathrm{M}$ Waites 'Age of consent and sexual citizenship in the United Kingdom: A history' in J Seymour \& P Bagguley (eds) Relating intimacies: Power and resistance (1999) 92. According to Waites, the term 'age of consent' is not a legal term, but rather convenient language 'which can be used with caution to describe minimum ages below which certain sexual acts are prohibited' (emphasis in the original).

4 Malawi Law Commission Report of the Law Commission on criminal justice reform on the review of the Penal Code (CAP 7:01) (2000).

5 Bill 17 of 2009: Penal Code (Amendment).

6 World Vision 'Children's rights in Malawi: Stakeholder report on Malawi Submission by World Vision for Universal Periodic Review, 9th Cycle, NovemberDecember 2010', http://lib.ohchr.org/HRBodies/UPR/Documents/session9/MW/ WVI_WorldVisionInternational.pdf (accessed 14 July 2016).

7 Constitution of the Republic of Malawi, 1994.

8 Gender Equality Act 3 of 2013 (Malawi). 
sexual and reproductive health and rights of everyone, including children. ${ }^{9}$

The article draws upon knowledge generated in the interdisciplinary field of childhood studies about the meanings of childhood and sexuality, and its intersections with human rights norms, to interrogate sections 138 and 160B and their implications for child and adolescent sexuality development, sexual health and rights. It employs a pro-feminist critique of gender to analyse the assumptions and rationale of the two provisions.

Section 23(6) of the Constitution defines a child as a person below the age of 18 years. ${ }^{10}$ United Nations (UN) bodies have consistently defined adolescence as the ages between 10 and 19 years. ${ }^{11}$ For purposes of this article, the term 'adolescence' is confined to persons between the ages of 10 and 18, so that the scope of discussion is limited to children as defined in the Constitution.

\section{Theorising childhood}

\subsection{Childhood}

There is consensus that Ariès was the first theorist to conceptualise childhood as a notion of which the meanings vary in time and context. ${ }^{12}$ The idea that childhood is not simply a natural category but, rather, historically and culturally constructed, has influenced the study and development of knowledge about children, especially in the interdisciplinary field of childhood studies. The notion of childhood as socially constructed suggests that there are multiple conceptions of childhood across different cultures, and even within cultures. The meanings of childhood have shifted with time.

The dominant meanings of childhood have been shaped by developmental approaches associated with the period in Europe described as modernity. ${ }^{13}$ Western conceptions of childhood were shaped by the social changes that took place during that period, including industrialisation, capitalism, and the rise of social class distinctions. Various scientific disciplines also proliferated during this period, including medicine and psychology. Drawing upon modernity's conceptions of childhood, Piaget's work in developmental

9 Sec 19 Gender Equality Act.

10 On 14 February 2017, parliament passed Bill 36 of 2016: Constitution (Amendment) raising the age of minority from 16 to 18 . The Bill was signed into law in April 2017.

11 World Health Organisation The health of youth, Document A42/Technical Discussions/2.

12 P Ariès Centuries of childhood: A social history of family life (1962).

13 CE Forth 'History, modernity' in M Flood et al (eds) International encyclopedia of men and masculinities (2007) 291. Forth describes modernity as 'a complex and interrelated cluster of social, political, cultural and economic developments that has characterised Western societies since the decline of the feudal era'. 
psychology provided an explanatory framework of childhood that has influenced the understanding of childhood in contemporary times. ${ }^{14}$ In Piagetian development psychology, 'children are perceived to proceed through a biologically predetermined set of linear cognitive developments, which correlate with chronological age, to reach the ultimate goal of adulthood'. ${ }^{15}$ Childhood, therefore, is constructed as a phase of 'becoming', a metaphorical state of immaturity and inferiority, and a stage of progression from irrationality to rationality, and from asexual to sexual. ${ }^{16}$

Hendrick traced the shifting concepts of childhood in Britain from 1800 to the 1990 s. According to Hendrick, the dominant discourse of childhood drew discursively on constructions of childhood that dominated certain historical periods, including the child as innocent and pure; the child as tainted by original sin and in need of redemption; the child as in need of protection from labour; and the child who was unlike child: the delinquent child. ${ }^{17}$ Childhood discourses progressively constructed children in opposition to and as dependent on adults. Schools were established to socialise and train children to become functional adults and to avoid delinquency or deviance. ${ }^{18}$ The state became more interventionist in the lives of children by creating various laws on children, including age of consent laws. ${ }^{19}$

The notion of Western childhood conjures up powerful images, such as immaturity, helplessness, passivity, asexuality, innocence, irresponsibility and incompetence, and justifies their control by adults under the guises of saving and protecting children, and acting in their best interests. ${ }^{20}$ However, constructing children as innocent and asexual masks the operation of power: the power to control, subjugate not only children but those who are deemed to be like children, or indeed to separate as 'other' those children who are 'unlike' children, such as children who have sex. ${ }^{21}$ Children who do not behave as adults expect them to are stigmatised and constructed as deviant.

14 A Prout \& A James 'A new paradigm for the sociology of childhood? Provenance, promise and problems' in A James \& A Prout (eds) Constructing and reconstructing childhood?: Contemporary issues in the sociological study of childhood (1997)10-11.

15 KH Robinson 'In the name of "childhood innocence": A discursive exploration of the moral panic associated with childhood and sexuality' (2008) 14 Cultural Studies Review 115.

16 D Archard Children: Rights and childhood (2015) 48.

$17 \mathrm{H}$ Hendrick 'Constructions and reconstructions of British childhood: An interpretive survey, 1800 to the present' in James \& Prout (n 14 above) 36-42.

18 Hendrick (n 17 above) 45.

19 Hendrick 50-51.

20 B Thorne "'Childhood": Changing and dissonant meanings' (2009) 1 International Journal of Learning and Media 21-22.

21 B Thorne 'Re-visioning women and social change: Where are the children?' (1987) 1 Gender and Society 86. 


\subsection{Adolescence}

Adolescence is a phase of childhood the meaning of which, similar to that of childhood, is socially constructed. The theories and ideas of Granville Stanley Hall, dubbed as the 'father of adolescence', have had a lasting influence on the conceptualisation of adolescence. ${ }^{22}$ Hall characterised adolescence as the age of 'storm and stress', and explained that adolescents are unstable, emotional and poor decision makers because of raging hormones. Hall's treatise on 'adolescence ${ }^{23}$ and the movement of the study of children 'invented' the institution of adolescence as that ideal age of development which, if properly administered, would contribute to the evolution of a healthy and superior human race. ${ }^{24}$ The idea of adolescence was premised on gender, racial and class lines. Hall and his followers saw adolescence as

a crucial point at which an individual (and society) jumped to a developed, superior, Western selfhood, or remained arrested in a savage state. Adolescence became the dividing line between rational, autonomous, and moral white bourgeois men, those civilised men who would continue the evolution of the race, and emotional, conforming, sentimental, or mythical others, namely primitives, women, and children. ${ }^{25}$

Hall and his followers promoted the study of school children to devise that kind of training or curriculum that would produce adolescents who were morally fit, physically strong and healthy to contribute to economic productivity. Hall advocated 'an economic logic of human health in which the nerve force of humans is limited, and one must not dissipate it in masturbation or other wasteful sexual activities' ${ }^{26}$

By characterising adolescence as 'storm and stress', adolescents are perceived primarily as bodies controlled by raging hormones. Such conceptualisation, linked with the idea that adolescents ought to be trained to produce a healthy and superior race, became the foundation for institutionalising schools as the ideal training ground and management of future citizens. In schools, pupils would be trained in a manner that would discourage such behaviour that would lead to degeneracy and inferior development, such as masturbation and 'wasteful sexual activities'. Schools, therefore, became masculinised and sexually-sanitised environments. ${ }^{27}$ It also extended the time that young people spend in schools, so that even when they attained sexual maturity, they were supposed to maintain discipline and behave like asexual beings.

22 N Lesko Act your age!? A cultural construction of adolescence (2012) 42.

23 GS Hall Adolescence: Its psychology and its relations to anthropology, sex crime, religion and education (1904).

24 Lesko (n 22 above) 46-47.

25 Lesko 46.

26 Lesko 55.

27 Lesko 68-69. 
Therefore, just like childhood, adolescence is more than a natural category, the meaning of which is defined by biology and physiology. Rather, it is a socially-constructed and political category that has been applied to persons based on age and the onset of secondary sexual characteristics, and inflects sociocultural ideologies shaped by historical factors. For instance, therefore, the stigma faced by pregnant learners in schools, as described by Shefer et al, is in part attributed to the vision of schools as institutions for management of the sexuality of adolescents, so that pregnant girls are constructed as 'failures' or deviant because of their sexual precocity. ${ }^{28}$ This also explains the anxiety schools face in teaching sexuality education, which is mostly focused on disease and danger, because sexuality education is used as a tool to control adolescents in order to prevent sexual degeneracy of society, as envisaged by Hall, rather than for empowering them. ${ }^{29}$

\section{Interaction of law and culture in shaping the discourses of child sexuality}

The social practices regulating sexual conduct of children existed in Malawi before the introduction of Western notions of an age of consent. The introduction of a Western system of regulation, therefore, created a pluralistic environment in which multiple regulatory systems coexist. In traditional Malawi, ${ }^{30}$ the most important and significant marker of attainment of adulthood is puberty and, in some cultural groups in Malawi, it is marked by initiation rites. ${ }^{31}$ At puberty, the child is recognised as capable of adult sexual conduct, and the initiation rites mark entry into adulthood. Generally, girls are taught to avoid sex with boys in case they become pregnant before marriage, which would bring shame and dishonour to the family. ${ }^{32}$ There is a stricter regulation of sexual conduct for the girl, through the social shaming of girls who have sex

28 T Shefer et al 'Teenage pregnancy and parenting at school in contemporary South African contexts: Deconstructing school narratives and understanding policy implementation' (2013) 31 Perspectives in Education 3-5.

29 C Macleod 'Danger and disease in sex education: The saturation of "adolescence" with colonialist assumptions' (2009) 11 Journal of Health Management 382.

30 The term 'traditional Malawi' is used here to mean contexts in which the social practices are predominantly of native rather than of Western origin.

31 AC Munthali \& EM Zulu 'The timing and role of initiation rites in preparing young people for adolescence and responsible sexual and reproductive behaviour in Malawi' (2007) 11 African Journal of Reproductive Health 154.

32 Munthali \& Zulu (n 31 above) 160. Amongst the Chewa, eg, special 'shaming' initiation rites that were performed for girls who had become pregnant before marriage, see JC Njeula 'A study on influence of traditional initiation practices to reduce spread of HIV and AIDS in Chileka, a rural area in Blantyre in Malawi' (2014) 1 International Journal of Research and Review 21. 
or have pre-marital pregnancies, but boys are relatively free to indulge in pre-marital sexual activities. ${ }^{33}$

There continues to be dynamic interaction between Western and traditional culture (and religion) ever since their coexistence, and they have influenced each other in shaping gender and sexuality discourses, including the way in which childhood and adolescent sexuality is understood in modern Malawi. The following example illustrates how public policy and culture interact to shape knowledge and discourse on adolescent sexuality. A report on a survey evaluating the implementation of the Youth Friendly Health Services (FHS) Programme captured the following sentiments from parents: ${ }^{34}$

In most parent FGDs, participants were against their children using contraceptive methods. Use of contraceptive methods was perceived as culturally inappropriate, particularly for youth aged below 15 years. The parents could also not understand why unmarried girls should use contraceptive methods. Some parents even stated that they would beat or stop paying the school fees of the young people under their care found to be using contraceptive methods.

It is interesting to note that parents attached significance to the age of 15 as the cut-off point for adolescents' access to contraceptives. But where did the 15 come from? In traditional Malawi, the significant event was menarche and not a particular age. One explanation is that at that time section 22 of the Constitution discouraged marriage of children below the age of $15 .{ }^{35}$ This might have shaped how parents conceptualise the sexuality of girls in such a manner that has imbued the age 15 with a significance that did not exist in traditional culture's conception of child sexuality.

The influence of Western laws on cultural practices has also been captured by Parikh in an ethnographic study of the development of age of consent law in Uganda, especially when the age of consent was raised to 18. Parikh found that the law was appropriated by fathers to control boys who are able to sexually access their daughters. Poor boyfriends would be threatened with prosecution, especially when the sexual intercourse ended up in the girl becoming pregnant. ${ }^{36}$ The age of defilement law, therefore, reinforced the cultural patriarchal control

33 AC Munthali et al Adolescent sexual and reproductive health in Malawi: A synthesis of research evidence (2004) 13.

34 Evidence for Action Evaluation of youth-friendly health services in Malawi (2014) 169.

35 Parliament has since passed a Bill to amend sec 22 to raise the age of marriage to 18.

36 SA Parikh "'They arrested me for loving a schoolgirl": Ethnography, HIV, and a feminist assessment of the age of consent law as a gender-based structural intervention in Uganda' (2012) 74 Social Science and Medicine 1779. Raising the age of sexual consent for adolescent females from fourteen to eighteen years old and increasing the maximum sentence to death by hanging. The amendment can be considered a macro-level intervention designed to address the social and health inequalities affecting young women and girls, particularly their 
of the sexuality of girls by their fathers, thereby contributing to the disempowerment of girls.

Sections 138 and 160B, therefore, reflect both cultural conceptions about children's sexuality, and shape societal attitudes about children's sexuality, and in ways that can reinforce social practices that disempower children. More than just regulating sexual conduct, these provisions constitute 'a framework for expectations and norms for parents and professionals working with young people, which informs how they seek to shape and influence young people's behaviour'. ${ }^{37}$ Therefore, it is important to understand the rationale and assumptions behind sections 138 and $160 \mathrm{~B}$ and their implications for the lives of children because, apart from regulating sexual conduct, these provisions shape certain culturally-specific meanings of childhood and adolescence. This means also investigating the colonial background of age of consent laws, the sociocultural contexts in which they originated, and the cultural context in which they were imposed.

\section{Development of sections 138 and 160B of the Penal Code and their sociocultural and political contexts}

\subsection{Section 138 before the 2011 amendments: Sexual intercourse with a girl below 13 years of age}

Section 138 came down though Ehrhardt's draft model Code, but its roots can be traced beyond the eighteenth century in the history of the development of English criminal law. According to Waites, the first minimum age of sexual intercourse in English law appeared in the Statute of Westminster of 1275 , which prohibited sexual intercourse with 'any maiden within age'. ${ }^{38}$ Scholars have interpreted this age to be 12 years. Following further legal developments, sexual offences became consolidated under the Offences Against the Person Act 1861. It included provisions prohibiting 'carnal knowledge' of a girl under 10 years, which was a felony attracting a maximum punishment of penal servitude for life, while carnal knowledge of a girl under 12 years was a misdemeanour, with a maximum sentence of

disproportionately high rate of HIV as compared to their male counterparts. While the intention of the law and aggressive campaign was to prosecute 'sugar daddies' and 'pedophile', the average age of men charged with defilement was twenty-one years old and many were believe to be 'boyfriends' in consensual sexual liaisons with the alleged victims. This article uses court records, case studies, and longitudinal ethnographic data gathered in east-central Uganda to examine the impact of the age of consent law at national and local levels, and specifically what the disjunctures between national intentions and local uses reveal about conflicting views about sexual privilege and rights. I argue that existing class, gender, and age hierarchies have shaped how the Defilement Law has been applied locally, such that despite the stated aim of 'protecting' young women, the law reinstates patriarchal privilege (especially against men of lower social class M Waites The age of consent: Young people, sexuality and citizenship (2005) 217.

38 Waites (n 37 above) 62. 
three years' penal servitude. ${ }^{39}$ The Offences Against the Person Act 1875 raised the age for sexual intercourse from 12 to 13 years. Further legislative reforms led to the raising of the age of consent to 16 years with the enactment of the 1885 Criminal Law Amendment Act.

Waites describes the cultural context in which age of consent laws were developed in Europe. The first to note is that children were in legal terms regarded as the property of parents rather than individuals entitled to rights. ${ }^{40}$ The development of laws regulating sexuality reflected culturally and historically-specific attitudes about gender, with the result that age of consent laws were fundamentally 'patriarchal in their conception, embodying male power and control over women and children, embedded in patriarchal heterosexuality understood as a system of social and legal property relationships and sexual relationships' ${ }^{41}$ Age of consent laws were designed to prohibit young girls from being sexually accessed to preserve their innocence, rather than to create a right to consent to sex. The formulation of the law reflected patriarchal and gendered conceptions of female and male sexuality "whereby "the beast" of male lust required legal containment to preserve the virtue of a passive, innocent female sexuality'. ${ }^{42}$ The law treated boys and girls differently based on the view that boys have an active whereas girls have a passive sexuality. ${ }^{43}$

Another aspect of the patriarchal basis of the law was that the girl was considered the property of her father and that the preservation of virginity was required to preserve the father's honour. ${ }^{44}$ The offence of defilement, therefore, was really for the protection of the father's property in the virgin girl, rather than her right to sexual autonomy. Criminal law, therefore, conceptualised 'defilement' in heteronormative terms and aimed at protecting girls from penile-vaginal sexual intercourse.

A further aspect of the age of consent laws is that they were race and class-based, and this is especially reflected in the developments that led to the raising of the age of consent from 13 to 16 years, through the efforts of the social purity reformers, whose rationale for raising the age of consent emerged out of the moral panic that young middle and upper-class 'white' virgins were being allured into prostitution. ${ }^{45}$ A Select Committee of the House of Lords was asked to investigate the allegation of prostitution of British girls. The Committee's view of the reasons for the prostitution attest to the

39 As above.

40 As above.

41 As above.

42 Waites (n 3 above) 97.

43 Waites (n 37 above) 69.

44 Waites (n 37 above) 64.

45 Waites (n 3 above) 96. 
gender-stereotypical, racial and class-based thinking behind the reform, and was captured as follows: ${ }^{46}$

A vicious demand for young girls; overcrowding in dwellings; immorality arising therefrom; want of parental control, and in many cases parental example; profligacy; and immoral treatment; residence, in some cases, in brothels; the example and encouragement of other girls slightly older; and the sight of the dress and money which their immoral habits have enabled them to obtain; the state of the streets in which little girls are allowed to run about, and become accustomed to the sight of open profligacy; and sometimes the contamination of vicious girls in schools.

Western laws introduced during colonialism, therefore, reflected the sociocultural and political contexts from which they originated. However, when they were imposed on Malawi during colonialism, they carried an additional significance. Colonial laws were not designed to respect the rights of the natives, but to advance the colonialists' imperialist project to manage the natives in a way that would be most productive for the capitalist economy. The colonial government was careful not to implement laws, for instance, governing social relationships, that would disturb too much the natives' way of life to avoid disruption of the labour the natives provided for the sustenance of the imperial capitalist economy. ${ }^{47}$ Therefore, over and above the purported intentions of the colonial law stated in the legislation books, colonial laws were designed to manipulate the natives for the colonialists' imperialistic agenda.

The original version of section 138 , therefore, must be understood in the context outlined above. The original version of section 138 reads as follows: 48

(1) Any person who unlawfully and carnally knows any girl under the age of thirteen years shall be guilty of a felony and shall be liable to imprisonment for life, with or without corporal punishment. ...

Provided that it shall be a sufficient defence to any charge under this section if it shall be made to appear to the court, jury or assessors before whom the charge shall be brought that the person so charged had reasonable cause to believe and did in fact believe that the girl was of or above the age of thirteen years.

One aspect to note is the heterosexist and gender-stereotypical meanings of sexuality inflected in the provision, which construct only girls as needing protection from sexual conduct. The choice of exporting to the colonies the age of consent of 13 years when in England it had been raised to 16 years reflects the class-based context of the 1885 reforms in England. Further, the colonial government

46 F Mead \& AH Bodkin Criminal Law Amendment Act, 1885, with introduction, notes and index (1885) 12.

47 TA Barnes 'The fight for control of African women's mobility in colonial Zimbabwe, 1900-1939' (1992) 17 Signs: Journal of Women in Culture and Society 589.

48 Sec 138 Penal Code (n 1 above), before the 2011 amendment. 
might have feared that raising the age of consent to 16 would be too disruptive of the social relationships of the natives in a context where menarche was the significant event that marked entry into adulthood.

Another aspect to note is that the law was formulated in a manner that constructed the girl as a passive subject, so that even the defence itself was from the perspective of the defendant boy or man who was accorded subjectivity, and not from the perspective of an agentic girl. Further, the use of the term 'unlawful' in the definition of the crime suggested that there were circumstances in which it would be lawful to have sexual intercourse with a girl of below 13 years. This shows that the provision was not really about protecting girls from being sexually accessed but, rather, for controlling the girl's sexuality.

Since the age of consent was so low and, in addition, according to section 14 of the Penal Code, a male of under the age of 12 years was deemed incapable of engaging in sexual intercourse, the gap for criminalising consensual sexual conduct between children was very narrow. This, however, changed when section 138 was amended in 2011.

\subsection{1 amendments}

Several amendments to the Penal Code were made in 2011, but only two are considered for purposes of the article. These are the amendment of section 138 and the introduction of section 160B. However, these sections should not be read in isolation from other related provisions.

\subsubsection{Section 138: Sexual intercourse with a girl below 16 years of age}

The amended section 138 reads as follows:

(1) Any person who carnally knows any girl under the age of sixteen years shall be guilty of felony and shall be liable to imprisonment for life.

(2) Any person who attempts to have carnal knowledge of any girl under the age of sixteen years shall be guilty of felony and shall be liable to imprisonment for fourteen years.

Provided that it shall be a sufficient defence to any charge under this section if it shall be made to appear to the court, jury or assessors before whom the charge shall be brought that the person so charged had reasonable cause to believe and did in fact believe that the girl was of or above the age of sixteen years.

The reasoning of the Law Commission in recommending that the age of consent to sexual intercourse be raised from 13 to 16 years was

[p]remised upon the provisions of section 22(8) of the Constitution which prescribes a minimum age of entering into marriage. Presently, that age is prescribed at fifteen years, but the Commission noted that the Law 
Commission on the Technical Review of the Constitution has recommended that the age be raised to sixteen years. ${ }^{49}$

It is rather interesting that the rationale was to tie the age of consent to sexual intercourse to the age of consent to marriage. Now that a constitutional amendment has since changed the age of consent to marriage to 18 years, it remains to be seen whether this development would prompt a review upwards of the age of consent to sexual intercourse from 16 to 18 years. ${ }^{50}$ It is the argument of the article, which will become clear below, that such a move would most likely not serve the best interests of children. On the other hand, when the Commission's recommendation to raise the age of consent to sexual intercourse was considered in parliament, the debates of members of parliament mostly focused on the moral panics about 'rampant' cases of child abuse and the need to protect children from male abusers. ${ }^{51}$

The new section 138 maintains the salient features of the colonial version. In fact, the amendment suspiciously resembles the 1885 Criminal Law Amendment Act in England, the main difference being that the offence in the Malawi version is a felony rather than a misdemeanour. However, it does not need much more explication to demonstrate that section 138 inflects patriarchal, heterosexist and gender-stereotypic notions of gender and sexuality.

One explanation for the uncritical appropriation of colonial baggage in the development of section 138 is that it resonates with certain cultural ideals that are also patriarchal, heterosexist and gender-stereotypical. For instance, girls are supposed to maintain virginity before marriage, while boys are let free to explore their sexuality. Restricting boys from sexually accessing girls resonates with the idea that the law should prevent marauding boys from 'defiling' the virginity of someone's daughter.

The amended section 138 also presents a novel challenge that was not apparent with the earlier version of the provision because the age of consent had been very low. The range of sexual relationships criminalised includes non-exploitative sexual intercourse between adolescents below the age of 16 years. According to the Malawi Demographic and Health Survey, 19 per cent of young men and 14 per cent of young women aged 15 to 24 first have sex before the age of 15 years. ${ }^{52}$ Therefore, because a significant number of adolescents

49 Malawi Law Commission Report of the Law Commission on criminal justice reform on the review of the Penal Code (CAP 7:01) (2000) 39.

50 Bill 36 of 2016: Constitution (Amendment).

51 Eg, the Malawi National Assembly Daily Debates (Hansard) 18 November 2010 (2010) 72 captured the following contribution to the debate by a member of parliament: 'Mr Speaker, Sir, it is clear from the language used in both paragraphs of section 138 that at the time this particular section was put in the Penal Code, it was inconceivable that grown men would defile one-year-old, two-year-old, fiveyear-old. Sadly, in recent times in the last few years, we have seen a proliferation of this heinous crime ...'

52 National Statistical Office (NSO) and ICF Malawi Demographic and Health Survey 2016-15 (2017) 210. 
engage in sexual intercourse by the age of 16, a blanket criminalisation of sexual intercourse with girls of below 16 also catches adolescent boys who have sex with their peers. Apart from the criminalisation aspect, it also has implications for sexual health and the rights of the adolescent, because the law can influence attitudes that stigmatise adolescents who are sexually active.

\subsubsection{Sexual activity with a child below 16 years of age}

The 2011 amendments introduced a new offence through section $160 \mathrm{~B}$, of which the first part is reproduced here, as it suffices for the discussion:

1 Any person who engages or indulges in sexual activity with a child shall be guilty of an offence and shall be liable to imprisonment for twenty-one years.

Sexual activity is defined in section 160 A to mean

sexual contact other than sexual intercourse (whether between persons of the same or opposite sex) in the form of genital, oral-genital, anal-genital contact or otherwise, masturbation, touching of genitals, buttocks or breasts, sadistic or masochistic abuse and other deviant sexual behaviour.

Section 160B was introduced to cover the lacuna left by section 138 which only deals with sexual intercourse. Section 160B (as read with section 160A) covers offences of a sexual nature other than sexual intercourse. ${ }^{53}$

Similar arguments raised in the discussion of the amended section 138 also apply here. Section 160B introduces a blanket criminalisation of sexual activities with a child below 16 years of age, including normative and non-exploitative sexual activity between children who are peers. It also conflates normative with non-normative sexual behaviour by including in the definition of sexual activity terms such as 'sadistic or masochistic abuse and other deviant behaviour'.

\section{Re-visioning children and adolescents as gendered and sexual subjects}

To reiterate, colonial age of consent laws were not aimed at protecting the rights of girls, but at the advancement of patriarchal and imperialist interests. It is significant that the voices of the subjects of concern, girls, were absent in the process of formulating these laws. ${ }^{54}$ Girls and children are constructed as non-autonomous and passive subjects of the law, requiring the benevolent and salvific acts of law makers (dominated by men) to save them from would-be

53 Malawi Law Commission (n 49 above) 45.

$54 \mathrm{H}$ Bannerji Inventing subjects: Studies in hegemony, patriarchy and colonialism (2001) 77. 
defilers (also dominated by men) through legislation. In the colonialist's scheme of things, girls and women were but objects for control and manipulation, and laws regulating sexual relationships were designed not to promote the rights of girls and women, but to pacify adult males. ${ }^{55}$ It is unfortunate, therefore, that the 2011 amendments merely appropriated and consolidated the colonial baggage.

It will be the ultimate argument of the article that sections 138 and $160 \mathrm{~B}$, and others like them, cannot be sustained under Malawi's commitment to advance gender equality and the rights of the child. However, the process of reform should be less about making additional laws than about how to fashion better age of consent laws that are not laden with patriarchal, heterosexist and genderstereotypical notions of sexuality. One way to think about this is to revisualise children as partners rather than passive subjects.

In her 1987 article, Thorne raises a challenge primarily directed at feminist theorising about how, despite developing complex critiques of gender, feminism has uncritically assumed meanings of childhood that were in fact problematically imbued with the very meanings the critiques attempted to challenge. ${ }^{56}$ Prout and James also pointed out that in the history of social science research, children (and women) had been 'muted' groups, not that there was an absence of interest in children but, rather, that it was not their voice that articulated these interests. $^{57}$ Indeed, political theories have often lumped women and children together as relegated to the margins, while men occupied centre stage as autonomous actors. ${ }^{58}$ James and Prout, therefore, urge that children be seen as

actively involved in the construction of their own social lives, the lives of those around them, and the societies in which they live. They can no longer be regarded as the passive subjects of structural determinations. ${ }^{59}$

Recreating age of consent laws that are truly in the best interests of children requires making them partners, which means regarding them as autonomous and agentic subjects.

\subsection{Making children partners in promoting gender equality and advancing sexual health}

Constructing males (and boys) as having power over girls and children reproduces unequal power relations. Angelides argues that power relationships should be understood not as a relationship in which some have power and others lack power, but where 'each

55 Bannerji (n 54 above) 83.

56 Thorne (n 21 above) 86.

57 Prout \& James (n 14 above) 7.

58 B Thorne 'From silence to voice: Bringing children more fully into knowledge' (2002) 9 Childhood 251.

59 A Prout \& A James 'Introduction' in Prout \& James (n 14 above) 4. 
subject is differentially marked and positioned in power and discourse structures', 60 so that '[d]ominance and submission are not fixed positions determined by the presence and absence of power'.61 Making this argument in the context of child sexual abuse, Angelides suggests that conceptualising children as lacking knowledge about sexuality and as powerless in relation to adults not only misconstrues the power relationship, but disempowers children by erasing their autonomy and agency. ${ }^{62}$ Sections 138 and 160B, therefore, are inherently flawed as they disempower girls and children by erasing their sexual autonomy and agency.

Further, constructing children and girls as sexually passive defeats the aim of making them partners in gender equality. The International Conference on Population and Development (ICPD) Programme of Action affirmed that

[r]esponsible sexual behaviour, sensitivity and equity in gender relations, particularly when instilled during the formative years, enhance and promote respectful and harmonious partnerships between men and women. ${ }^{63}$

This would be possible if children are recognised as gendered and sexual subjects, and are supported throughout their development so that by the onset of adolescent sexual activity they are able to relate to others in a manner that recognises each person's dignity.

\subsubsection{Children as sexual and gendered}

Although adults sometimes implicitly recognise children as potentially sexual, they tend to perceive children as nonsexual despite the fact that children do actively engage in gendered relations of power, and invest in sexual relationships, including sexual pleasure. ${ }^{64}$ Children are not passive in matters of gender and sexuality. Bhana's research about young children of below the age of 10 years reveals a common misconception of adults that gender and sexuality do not matter to young children until they are older. According to the views of teachers of primary school children that Bhana interviewed, 'gender, doesn't matter to young children ... children are children'; 65 they are 'just

60 S Angelides 'Feminism, child sexual abuse, and the erasure of child sexuality' (2004) 10 GIQ: A Journal of Lesbian and Gay Studies 151.

61 Angelides (n 60 above) 152.

62 Angelides 158.

63 Report of the International Conference on Population and Development (ICPD) UN Doc A/CONF.171/13 (1994) para 7.34.

64 D Bhana 'Love, sex and gender: Missing in African child and youth studies' (2017) 42 Africa Development 251-252; P Talavera 'The myth of the asexual child in Namibia' in S Lafont \& D Hubbard (eds) Unravelling taboos: Gender and sexuality in Namibia (2007) 61-62 66). In his research, Talavera found that children amongst the Ovahimba and Ovaherero cultural groups of Namibia play games that may involve sexual acts, and most probably sexual pleasure. However, adults do not consider children as sexual.

65 D Bhana Gender and childhood sexuality in primary school (2016) 27. 
kids ... still young' ${ }^{66}$ However, as Bhana remarks, this attitude masks the operation of power because the teachers 'cannot see the child as sexual/gendered and constructing sexuality and gendering with others, nor can they challenge the continual naturalisation of gender differences and unequal relations of power' ${ }^{67}$ Further, such discourses of childhood innocence and asexual justify unwarranted control to prevent children from perceived dangers of (sexual) corruption, which causes teachers, for instance, to avoid addressing the topic of sexuality with children. ${ }^{68}$

Despite constructing children as non-gendered, Bhana found that teachers ascribed certain behaviours as natural to boys and others natural to girls. Boys were perceived to be naturally aggressive, adventurous and better at mathematical subjects, while girls were constructed as shy, reserved and more talkative. By naturalising behaviours as masculine or feminine, teachers unwittingly reinforced hegemonic masculine dominance and the subjugation of girls, on the basis that gender inequality is natural, and efforts to transform would be futile. ${ }^{69}$

Analogously, laws that construct children (and girls) as sexually passive, and as objects for the law to save from danger, including from normative sexual conduct, reinforce hegemonic masculinities. The important step towards law reform is to re-envisage children as gendered and sexual subjects.

\subsubsection{Childhood sexual conduct and sexual health}

Childhood sexuality is a political and contested topic as it tends to be shaped by moral panic about adults sexually abusing children. Yet, children cannot then be relegated to the asexual zone, as sexuality development is a necessary feature of human development. Sexuality has a wide dimension, and physical sexuality in relationships with others is just one aspect. ${ }^{70}$ Sexuality is integral to every person's life, young or old, child or adult. However, as children grow older, physical intimacy may become important for their sexuality development.

There are positive reasons for discouraging early sexual debut. An important question, however, is how to use criminal law to regulate

\section{As above.}

67 As above.

68 Bhana (n 65 above) 28.

69 Bhana 29.

70 This article adopts the following definition of sexuality in World Health Organisation Defining sexual health: Report of a technical consultation on sexual health, 28-31 January 2002 (2006) 5: '[A] central aspect of being human throughout life encompasses sex, gender identities and roles, sexual orientation, eroticism, pleasure, intimacy and reproduction. Sexuality is experienced and expressed in thoughts, fantasies, desires, beliefs, attitudes, values, behaviours, practices, roles and relationships ... Sexuality is influenced by the interaction of biological, psychological, social, economic, political, cultural, legal, historical, religious and spiritual factors.' 
childhood sexual conduct without infringing on the rights of the child, especially the right to sexual health, ${ }^{7 \top}$ which is an important aspect of childhood sexuality development. In Teddy Bear Clinic for Abused Children $v$ Minister of Justice and Constitutional Development, ${ }^{72}$ one of the questions the Court addressed was whether criminalising consensual sexual conduct between adolescents was necessary to achieve the aim of protecting adolescents from harmful sexual intercourse. The Court disagreed with the respondents, who argued to maintain criminalisation. Apart from the fact that it infringed on a host of rights, including the rights to dignity, privacy, bodily and psychological integrity and health care services, the Court was concerned that young people who have sexual conduct would be stigmatised, and denied support. ${ }^{73}$ This is one of challenges with the formulation of sections 138 and $160 \mathrm{~B}$ because, by constructing children of below 16 years as incapable of sexual activity or intercourse, the law potentially facilitates the creation of stigmatised identities: children who have sexual intercourse and activity below the age of 16. This could influence parents, educators and health providers to perceive such children as abnormal, failures or deviant.

The Kenyan case of Martin Charo $v$ The State illustrates the creation of a stigmatised subjectivity. In this case, a girl of 14 had voluntary sexual intercourse with a man almost 10 years older. He was charged and convicted of the offence of defilement under Kenyan law. ${ }^{74}$ On appeal, the Court quashed the conviction. The Court interpreted the law to mean that a child of below the age of 18 had no capacity to consent to sex. Therefore, in the Court's opinion, a girl who voluntarily engages in sex behaved like a grown woman, and did not deserve the protection of the law. The Court effectively constructed the girl as a deviant child because she expressed sexual desire and agency.

Sections 138 and 160B would most likely perpetuate such stigma against children who engage in sexual activity. This has a potentially negative influence on the attitudes of parents, teachers and health providers toward sexually-active children. Therefore, it is submitted that sections 138 and $160 \mathrm{~B}$ promote harmful practices toward children, defined under the GEA as

71 The definition of sexual health from World Health Organisation (n 70 above) 5 is adopted: '[A] state of physical, emotional, mental and social well-being in relation to sexuality; it is not merely the absence of disease, dysfunction or infirmity. Sexual health requires a positive and respectful approach to sexuality and sexual relationships, as well as the possibility of having pleasurable and safe sexual experiences, free of coercion, discrimination and violence.'

72 CCT 12/13 [2013] ZACC 35 (Constitutional Court of South Africa).

73 In para 45 of the judgment, the Court was of the view that '[w] hat is of utmost importance is ensuring that children are appropriately supported by the adults in their lives, to enable them to make healthy choices ... If children are not made to feel that there are safe environments within which they can discuss their sexual experiences, they will be stripped of the benefit of guidance at a sensitive and developmental stage of their lives.'

74 Sec 8(1)(3) Sexual Offences Act 3 of 2006 (Kenya). 
a social, cultural, or religious practice which, on account of sex, gender or marital status, does or is likely to -

(a) undermine the dignity, health or liberty of any person; or

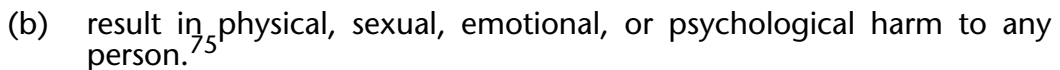

Further, by treating boys and girls differentially, section 138 not only conflicts with the Gender Equality Act, but also with the Constitution. Sections 138 and 160B, therefore, are contrary to the rights of children as envisaged by section 23 of the Constitution, which provides as follows: ${ }^{76}$

All children, regardless of the circumstances of their birth, are entitled to equal treatment before the law, and the best interests and welfare of children shall be a primary consideration in all decisions affecting them.

C̆hildren are entitled to be protected from economic exploitation or any treatment, work or punishment that is, or is likely to -

be harmful to their health or to their physical, mental or spiritual or social development.

\section{A balancing act: Protection versus self-protection}

\subsection{Right to protection}

In General Comment 20, the Committee on the Convention on the Rights of the Child (CRC Committee) reminds states of the obligation to protect children up to the age of 18 from exploitation of all kinds, and to 'balance protection and evolving capacities in determining the legal age for sexual consent'. ${ }^{77}$ The rationale of age of consent laws is to protect children from potentially exploitative sexual relationships. The child's vulnerability is the central concern. The child is vulnerable because he or she has not yet attained the capacity for selfdetermination in relation to sexual relationships. Failure to protect the child, therefore, would expose the child to risks of harm due to their

75 Sec 3 Gender Equality Act.

76 Sec 23 Constitution (n 7 above).

77 CRC Committee General Comment 20: The implementation of the rights of the child during adolescence UN Doc CRC/C/GC/20 (6 December 2016) para 40. The concept of evolving capacities is articulated in art 4 of the CRC as follows: 'States Parties shall respect the responsibilities, rights and duties of parents or, where applicable, the members of the extended family or community as provided for by local custom, legal guardians or other persons legally responsible for the child, to provide, in a manner consistent with the evolving capacities of the child, appropriate direction and guidance in the exercise by the child of the rights recognized in the present Convention.' In the African Charter on the Rights and Welfare of the Child (African Children's Charter), it is defined in art 9(2) as follows: 'Parents, and where applicable, legal guardians shall have a duty to provide guidance and direction in the exercise of these rights having regard to the evolving capacities, and best interests of the child.' Malawi has ratified both the CRC and the African Children's Charter. 
immaturity. At this stage, the child is wholly reliant on external rather than inherent resources for protection. In this case, therefore, the child is treated as a passive subject.

The right to protection entails that states enact laws that prevent other persons from engaging in sexual activity with the child. Sections 138 and $160 \mathrm{~B}$ provide this kind of protection. However, the incapacity of the child is not static but evolving. An important challenge, therefore, is where to set the age of consent. If the bar is set too low, it would expose many young children to harm and risk. Setting it too high may also unjustifiably interfere with the adolescent's evolving autonomy. ${ }^{78}$ Almost all jurisdictions, therefore, have set a 'minimum age' below which it always is criminal to engage in sexual conduct with a child as they are incapable of consenting to the sexual act, and incapable of protecting themselves from harm. ${ }^{99}$

Some jurisdictions, such as that of South Africa, have opted for a multi-stage age of consent framework rather than a single age of consent model. South Africa recognises that a child of 12 years and above could give some limited consent, and at 16 can give full consent. Sexual activity with a child of below 12 is prohibited, but peers in the age range of 12 and above but below 16 are not criminalised for engaging in non-exploitative sexual activity with peers of within the age range of 12 and 16 years. ${ }^{80} \mathrm{~A}$ person of 16 and above, however, cannot engage in sexual activity with a child more than two years younger.

The advantage of South Africa's multistage model is that it is better able to strike that balance between protection and self-protection. Children within the 12 to 16 years age range are recognised as both vulnerable and in need of protection, and as having an evolving capacity which they can exercise in relation to peers. By contrast, Malawi's model denies sexual capacity to a child of below 16, and criminalises adolescents for engaging in non-exploitative sexual intercourse and sexual activity with peers. Enforcing such a law would result in prosecuting adolescents, as was the case for a boy of 16 years in Kenya who was prosecuted for having sex with a girl of 16. In CKW $v$ Attorney-General, 81 the boy challenged the state's action. He argued before the High Court that his prosecution discriminated against him on the basis of age, because adults are not criminalised for engaging in consensual sex. Unfortunately, the Court disagreed with him, and was of the view that the law was there for the protection of children against the harms of sexual intercourse.

78 H Graupner 'Sexual consent: The criminal law in Europe and overseas' (2000) 29 Archives of Sexual Behaviour 418.

79 Graupner (n 78 above) 418.

80 Secs 15 and 16 of the Criminal Law (Sexual Offences and Related Matters) Amendment Act, 2007 as amended by the Criminal Law (Sexual Offences and Related Matters) Amendment Act Amendment Act 5 of 2015 (South Africa). 
In State $v$ Brian Masuku, 82 Tsanga J of the High Court of Zimbabwe lamented the harshness of the law on adolescents: ${ }^{83}$

The facts upon which he was convicted are commonplace among sex experimenting youths. He was 17. She was 15 . They were boyfriend and girlfriend ... Unlike in some jurisdictions, ours does not exempt from prosecution adolescent violators of such provisions when the parties are within a similar age bracket by two or three years above the minimum. Youthful violators over 16 have to deal with the actuality of punishment which is often tempered down due to their age where the circumstances permit. Sentences however, can still be harsh.

Rubin reminds us that this harshness of sex laws is not because laws of nature demand it, but because societies choose to enforce hegemonic notions of sexuality in the name of preserving dominant notions of social morality. ${ }^{84}$ This needless harshness toward adolescents was one of the concerns Justice Sisi Kampepe considered in the Teddy Bear Clinic case, that adolescents were unjustifiably exposed to the harshness of the justice system, and labelled as sexual offenders for engaging in developmentally normative sexual conduct. ${ }^{85}$ Justice Kampepe accepted the applicants' argument that it was not necessary to prosecute adolescents who have non-exploitative sexual conduct with other adolescents, to achieve the public policy aim of protecting children from sexual abuse. The CRC Committee has also similarly advised states that they should avoid criminalising adolescents who engage in consensual and non-exploitative sex. ${ }^{86}$

It could be argued that sections 138 and $160 \mathrm{~B}$ be maintained but tempered by a policy of non-prosecution of adolescents who engage in non-exploitative sex. This, however, still leaves children in precarity, because the law could still be enforced at any time. Most importantly, the law influences social attitudes and practices, and the existence of legal provisions that construct adolescents below 16 as without sexual agency can stigmatise children who are sexually active. Reference is again made to the Charo case discussed above, where the Court's opinion rendered a sexually-active girl deviant.

\subsection{Right to self-protection}

Commenting on the right to participation of the child, the CRC Committee has stated that '[b]y being guaranteed the right to be heard, to challenge rights violations and to seek redress, adolescents are enabled to exercise agency progressively in their own protection'. ${ }^{87}$ As capacity is evolving, children should be protected,

82 [2015] ZWHHC 106, CRB B467/14 (High Court of Zimbabwe).

83 Masuku (n 82 above) (judgment not paragraphed).

84 G Rubin 'Thinking sex: Notes for a radical theory of the politics of sexuality' in C Vance (ed) Pleasure and danger: Exploring female sexuality (1984) 277.

85 Teddy Bear Clinic (n 72 above) para 54.

86 CRC Committee General Comment 20: The implementation of the rights of the child during adolescence UN Doc CRC/C/GC/20 (6 December 2016) para 40.

87 CRC Committee General Comment 20 (n 86 above) para 19. 
and simultaneously, supported to progressively protect themselves. The role of the state, therefore, is to nurture and support the child as the child progressively attains the capacity to avoid and manage risks to sexual health in negotiating sexuality development. In interpreting article 24 of the CRC on right of the child to the enjoyment of the highest attainable standard of health, the CRC Committee affirmed that the right to health of the child entails freedoms and entitlements, and that these 'freedoms, which are of increasing importance in accordance with growing capacity and maturity, include the right to control one's health and body, including sexual and reproductive freedom to make responsible choices'. ${ }^{88}$ The 'entitlements include access to a range of facilities, goods, services and conditions that provide equality of opportunity for every child to enjoy the highest attainable standard of health'. ${ }^{89}$ While protection requires criminal law to limit sexual access and activity with the child, self-protection requires states to create a supportive environment for the adolescent to safely relate to other adolescents.

For children, therefore, the right to protection and self-protection should operate simultaneously in harmony. The challenge is that sections 138 and $160 \mathrm{~B}$ emphasise the right to protection only, in which the child of below 16 years is treated as a sexually-passive subject. Therefore, these sections potentially preclude the aspect of self-protection, and thus fail to envisage the creation of a supportive environment for the sexually-active child, where 'sexually active' should be understood more broadly than just sexual intercourse.

Constructing children as legally incapable of consenting to sexual activity when in fact they have an evolving capacity to make certain decisions about their sexuality is not merely unfortunate. It conjures limitations on the child's enjoyment of sexual health and sexual rights. Sexually-active children may not receive the guidance and support necessary for them to develop their capacity for sexual selfdetermination. ${ }^{90}$ Caregivers and parents may assume restrictive attitudes around children's sexuality and fail to provide this support. Anxiety about adolescent sexuality that sometimes forms the basis of public policy on childhood sexuality creates a self-fulfilling prophecy, as the disconnect with children results in failure to support them. The consequence of failure to support children is unwanted or unprotected sex, and the sequelae are common knowledge; unwanted pregnancies, unsafe abortions and sexually-transmitted infections, including HIV.

88 CRC Committee General Comment 15: The right of the child to the enjoyment of the highest attainable standard of health (art 24) UN Doc CRC/C/GC/15 (17 April 2013) para 24.

89 As above.

90 Teddy Bear Clinic (Constitutional Court) (n 72 above) para 47. 
The Gender Equality Act recognises the sexual health and rights of all, including children, in section 20(1), which provides that every health officer (provider) shall

(a) respect the sexual and reproductive health rights of every person without discrimination;

(b) respect the dignity and integrity of every person accessing sexual and reproductive health services;

(c) provide family planning services to any person demanding the services irrespective of marital status or whether that person is accompanied by a spouse. ${ }^{91}$

Section 20(1)(c) of the Gender Equality Act is designed to ensure the inclusion of unmarried adolescents who have historically been discriminated against in the provisions of sexual health services. Section 138 of the Penal Code, however, might send a conflicting message for the health provider who is expected to comply with section 20 of the Gender Equality Act. For instance, a health provider may face a dilemma if confronted by 15 year-old girl seeking sexual health care, who has an active sexual relationship with her 16 year-old boyfriend, as the health provider may consider prioritising protecting the girl from sexual intercourse rather than supporting her to protect herself.

\section{Rethinking age of consent provisions in Malawi's Penal Code}

For the reasons set out in the article, and in line with General Comment 15 of the CRC Committee, advising states that laws be assessed and repealed where necessary, if they have a potentially discriminatory impact on the right to heath of the child, ${ }^{92}$ as well as the exhortation of the ICPD Programme of Action to promote responsible sexual behaviour, sensitivity, and equity in gender relations from early childhood, ${ }^{93}$ it is submitted that sections 138 and $160 \mathrm{~B}$, as well as associated provisions, be reviewed. Their formulation potentially negates the efforts to promote gender equality and the sexual health and rights of the child.

This article recommends that in reviewing the age of consent provisions, and any associated provisions, the relevant bodies undertaking the review processes should aim at involving children to the extent possible in creating age of consent laws that are childcentric, so that the law does not over-represent adult anxieties and moral panics about children's sexual activities. The new law must be aligned to gender equality, and principles of the rights of the child,

91 Gender Equality Act (n 7 above) sec 20.

92 CRC Committee General Comment 15 (n 88 above) para 94.

93 ICPD Programme of Action (n 63 above). 
and should avoid inheriting patriarchal, gender-stereotypical and heterosexist meanings of sexuality that informed the 2011 amendments.

Finally, it ought to be acknowledged that criminalisation is a blunt tool for promoting gender equality and the sexual health of children. ${ }^{94}$ Indeed, as Skelton comments, '[i]f the state wants to play a role in delaying sexual debut, its tools should not be police and courts, but rather increased provision of education, counselling, and reproductive health services'. ${ }^{95}$ Overreliance on criminal law to guarantee optimum sexual health development of children, or as a magic bullet to solve the 'rampant' child sexual abuse, is misplaced and will achieve blunted results. Criminal law should best be envisioned as support for other promotional measures that include providing sexuality education and sexual health services to children, and from early childhood, not just at the onset of puberty. Criminal law and other policies on gender equality and sexual health of children, therefore, must be harmonised to ensure the right of the child to protection from the harms of sexual intercourse, and support to children to exercise choice about sexual relationships to the extent of their evolving capacities. ${ }^{96}$ Most importantly, in developing laws and policies on gender and sexuality, children ought to be conceptualised as partners in promoting gender equality and sexual health, rather than objects of adult-centred interests and control.

\footnotetext{
94 Archard (n 16 above) 151.
}

95 A Skelton 'Balancing autonomy and protection in children's rights: A South African account' (2016) 88 Temple Law Review 88904.

96 An example of harmonisation is that the Children's Act 38 of 2005 (South Africa) grants all children the right to access health information, and children of 12 years and older the right to access condoms, which is in harmony with the age of consent provisions in the criminal law which recognises that a child of 12 years and above may have capacity to engage in sexual conduct. However, having a good law is one thing, but implementing it with all the stakeholders is quite another; eg, to have children access condoms in schools is a still a challenge, as the authors attest in J Han \& ML Bennish 'Condom access in South African schools: Law, policy, and practice' (2009) 6 PLoS Medicine. 